\title{
Preoperative Management of Patients Undergoing Liver Resection for Perihilar Cholangiocarcinoma
}

\author{
Mariano Cesare Giglio ${ }^{1,2}$, Federico Tomassini ${ }^{1}$, Sara Maritato ${ }^{1}$, Giammauro Berardi ${ }^{1}$, \\ Nikdokht Rashidian ${ }^{1}$, Roberto Montalti ${ }^{3}$, Roberto Ivan Troisi ${ }^{1,2}$
}

'Department of General, Hepato-Biliary and Liver Transplantation Surgery, Ghent University Hospital Medical School, Ghent, Belgium

${ }^{2}$ Department of Clinical Medicine and Surgery, Federico II University, Naples, Italy ${ }^{3}$ Hepatobiliary and Abdominal Transplantation Surgery, Department of Experimental and Clinical Medicine, Università Politecnica delle Marche, Ancona, Italy

\section{ABSTRACT}

Surgical resection with negative margins is the standard treatment for perihilar cholangiocarcinoma whenever possible. Patient's frequent low performance status at presentation and need of extended resections require optimization of the patient's condition in the preoperative setting. Biliary drainage is mandatory in case of cholangitis, jaundice-related liver insufficiency, malnutrition or renal failure. Drainage is also necessary in case of portal vein embolization (PVE), in order to improve regeneration of the future liver remnant (FLR). Unilateral drainage of the FLR should be obtained, while bilateral drainage is required in case of cholangitis, slow reduction in bilirubin and uncertainty about the side of resection. The technique for biliary drainage should be decided according to the local expertise and other factors (need of further evaluation of tumour extension, patient's compliance, necessity of bilateral drainage). Preoperative symbiotics-reduce postoperative infections. PVE is safe and increases the safety of surgery in case of extended liver resections. It is indicated in case of low FLR volume $(<40 \%)$, low FLR function or in case of previous cholangitis. ALPPS is not recommended in case of PHC.

Key words: perihilar cholangiocarcinoma, Klatskin, biliary drainage, portal vein embolization, preoperative management

\section{INTRODUCTION}

Surgical resection with negative margins is the preferred treatment for patients with Perihilar cholangiocarcinoma (PHC). PHC often requires complex surgical resections with high rates of morbidity and mortality (1). Despite improvements in the recent years, postoperative mortality remains high and represents one of the highest among abdominal surgical procedures (1).

Patients with PHC often present with a poor performance status, which increases surgical risk. Optimal management of these patients in the preoperative setting can, therefore, have a significant impact on postoperative

\author{
Corresponding author: \\ Roberto I. Troisi, MSc MD Ph.D. FEBS \\ Department of Clinical Medicine and \\ Surgery, Federico II University, Naples \\ Italy \\ via Sergio Pansini, 580131 Naples Italy \\ E-mail: roberto.troisi@unina.it
}

Received: 01.06.2018

Accepted: 25.06.2018

Copyright (1) Celsius Publishing House www sgo-iasgo.com 
outcomes. This review will focus on available interventions to optimize patients condition prior to surgery for PHC.

\section{BILIARY DRAINAGE VS NO DRAINAGE}

Jaundice is the most common symptom of presentation in patients with $\mathrm{PHC}(2)$. The necessity of routine pre-operative biliary drainage (PBD) in these patients has been a topic of controversial debate.

Theoretic advantages of PBD include improved liver function and regeneration with decreased risk of post hepatectomy liver failure (PHLF) $(3,4)$, reduction of systemic toxicity (5) and reversal of impaired immune function to reduce subsequent risk of infections (6). These experimental data are supported by clinical data showing increased morbidity and mortality in patients undergoing extended liver resections without PBD (79). Many authors, mostly from Asia, routinely perform PBD in jaundiced patients undergoing major liver resection. Of note, Nagino et al. reported PBD even in 69 non-jaundiced patients showing only intrahepatic biliary dilatation (10).

On the other side, PBD carries some risks, which could delay or prevent surgical treatment (e.g. cholangitis, pancreatitis) and compromise patients outcomes (e.g. drain track tumor seeding) $(11,12)$. These risks should be taken into account, especially considering some series showing the safety of liver resections for $\operatorname{PHC}$ without $\operatorname{PBD}(13,14)$.

A number of randomized controlled trials has analyzed the impact of PBD in jaundiced patients undergoing surgery for malignancy. However, these studies focused mainly or exclusively on patients undergoing pancreatoduodenectomy, making their findings not applicable to those undergoing liver resection $(15,16)$. Hence, high-level evidence on this topic is missing, while lower-level evidence remains controversial (15). This becomes evident even in national guidelines from different countries (17), where pre-operative PBD for PHC is recommended (8) or not recommended (18).
Nonetheless, mostly all authors recommend PDB in selected group patients with cholangitis, hepatic insufficiency, jaundice-related malnutrition or renal failure, and in patients undergoing neoadjuvant chemotherapy $(19,20)$. PBD is also recommended when portal vein embolization (PVE) is needed in presence of a small future liver remnant (FLR) (20).

\section{ENDOSCOPIC VS PERCUTANEOUS DRAINAGE}

There are currently 3 options for PBD, which include percutaneous transhepatic biliary drainage (PTBD), endoscopic biliary drainage (EBD) and endoscopic nasobiliary drainage (ENBD) (table 1, fig. 1).

\section{Percutaneous transhepatic biliary drainage}

PTBD has been associated with a high success rate in relieving cholestasis with a percentage ranging from $58 \%$ and $100 \%$ of patients undergoing the procedure and a median time from the first attempt to normal bilirubin level of 41 days compared to 61 days in the EBD (21-24). Furthermore, a lower risk of cholangitis compared to the other available options has been reported with rates between $8 \%$ and $22 \%$ and an overall incidence of $16.6 \%$ compared to $30.5 \%$ in EBD $(22,23,25,26)$. However, PTBD is associated with complications related to its invasiveness. Aside from patient discomfort, the risk of hemorrhage should be considered as this is reported with an incidence of $2-15 \%$ in major series $(21,23)$. Furthermore, some cases of cancer dissemination along the catheter tract have been reported, with rates up to $6 \%(12,23,27)$. An advantage of PTBD is that it can provide better delineation of the tumor extent within the liver for a more accurate operative planning (20).

\section{Endoscopic biliary drainage}

EBD is considered a less invasive option for malignant obstructive jaundice and it is currently

Table 1 - Outcomes and complications of different methods for pre-operative biliary drainage

\begin{tabular}{lccccc}
\hline & \multicolumn{5}{c}{ Outcomes and complications } \\
\hline & Success rate & Cholangitis & Pancreatitis & Bleeding & Cancerdissemination \\
\hline Percutaneoustranshepaticbiliarydrainage & $58-100 \% 26$ & $8-21.4 \% 26$ & $0-7 \% 26$ & $1-7 \% 26$ & $3-5.2 \% 12,26$ \\
\hline Endoscopic biliary stenting & $50-100 \% 26$ & $12.1-65 \% 26$ & $0-21 \% 26$ & $0-6.8 \% 23,26$ & $0 \% 26$ \\
\hline Endoscopicnasobiliarydrainage & $39 \% 28$ & $15.3-29.4 \% 26$ & $0-14 \% 26$ & $0 \% 22,28,29$ & $0 \% 26$ \\
\hline
\end{tabular}



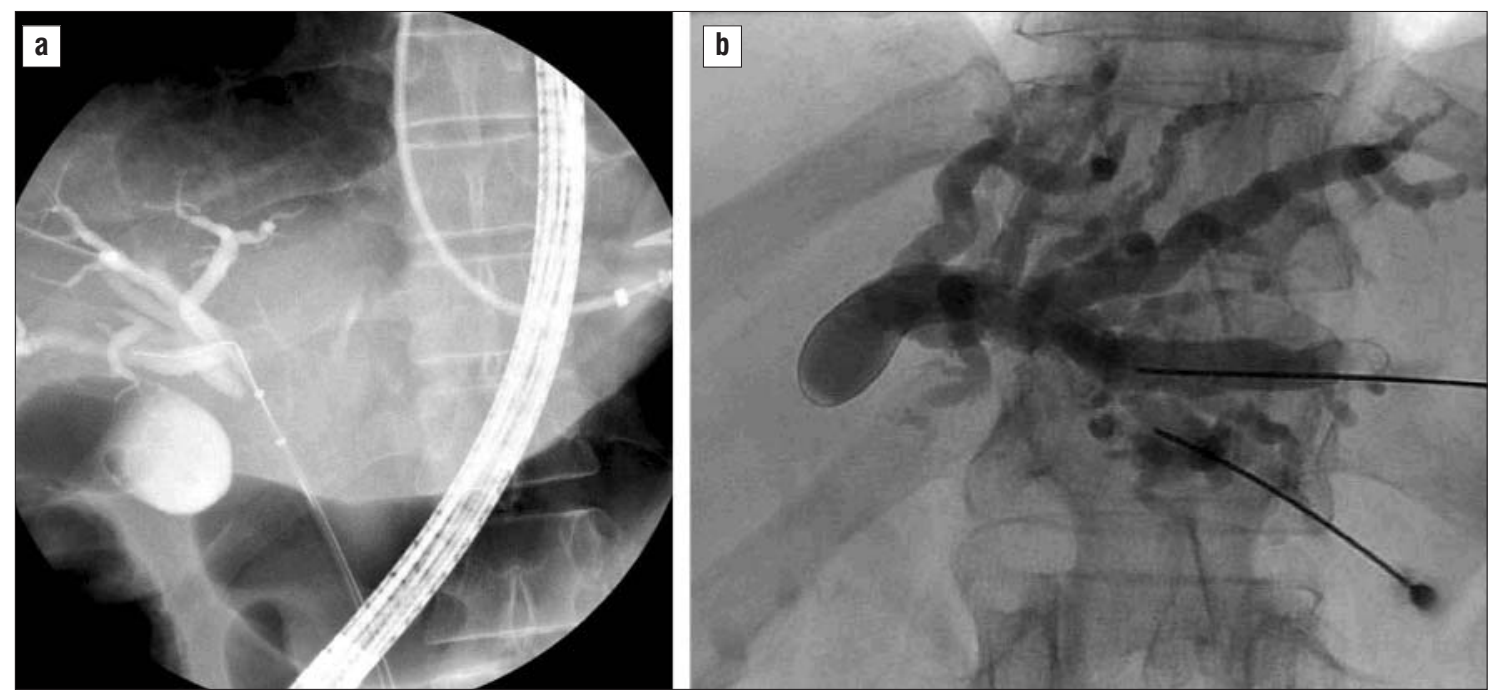

Figure 1 - Preoperative biliary drainage in patients with peri-hilar colangiocarcinoma

a. Endoscopic biliary drainage. A guide wire is advanced through the stenosis in the right biliary system b. Percutaneous trans-hepatic biliary drainage. The left biliary system is opacified following double puncture in order to obtain double percutaneous drainage of the future liver remnant.

chosen as the first option in several centers. The success rate in resolving cholestasis ranges from $57 \%$ and $100 \%$ but despite this, a higher rate of cholangitis $(12-65 \%)$ has to be considered because of ascending bacterial contamination (21-23). Furthermore, procedure-related complications such as duodenal perforation, hemorrhage (1\%) and pancreatitis (4-21\%) have been reported $(21-23,28)$. It has to be mentioned that more than half of patients undergoing EBD will later require PTBD to achieve the required therapeutic effect (20).

\section{Endoscopic nasobiliary drainage}

ENBD is an alternative technique of EBD that allows reducing the rate of ascending cholangitis because of the limitation of bacterial contamination from the gut. In fact, the rates of cholangitis related to the procedure have been reported to be around $15-29 \%(22,28,29)$. Pancreatitis was reported to range between $0-14 \%$ and no hemorrhages related to the procedure were shown $(22,28,29)$. A possible drawback of ENBD could be the related to the nasal catheter causing discomfort and nasopharyngeal irritation (22).

\section{UNILATERAL VS BILATERAL DRAINAGE}

Independently of the technique, unilateral drainage of the FLR is considered sufficient and is recommended by most of the authors $(8,30-32)$. This is possible as nowadays $\mathrm{CT}$ and MRCP allow planning the side of resection in most of the cases before biliary drainage. PBD limited to the FLR facilitates also is hypertrophy, in case of PVE.

Bilateral drainage should be obtained when the type of hepatectomy (and thus FLR) cannot be established before PBD, when a cholangitis develops in the non-drained hemi-liver, or when, after unilateral drainage, the diminution of bilirubin is slow (15).

\section{INTERNAL VS EXTERNAL DRAINAGE, BILE REINFUSION, SYMBIOTIC TREATMENT}

In case PTBD is chosen, bile drainage can be either external or internal.

Internal drainage, with the catheter passing through the stenosis into the common bile duct or the duodenum, has the advantage of restoring physiological bile flow to the bowel, thus improving liver regeneration and function and maintaining the integrity of the intestinal barrier (33-35).

External drainage has the advantage of reducing the risk of ascending cholangitis. Eastern authors recommend bile reinfusion orally or through nasogastric tube $(8,35,36)$, although the level of evidence supporting this recommendation is not high.

The preoperative oral administration of synbiotics (Lactobacillus casei, Bifidobacterium breve, and galactooligosaccharides) for two-weeks, has been shown to improve immune responses, attenuate postoperative inflammatory response and reduction of postoperative infectious complications (37). 


\section{FUTURE LIVER REMNANT EVALUATION AND RISK OF POSTOPERATIVE LIVER FAILURE}

Nimura and colleagues introduced in the early '90s the concept of routine segment 1 resection for surgical treatment of PHC (38), demonstrating an improvement in the 5 -year survival rate $(40 \%$ vs $5 \%)(38,39)$. Extended hepatectomies are nowadays considered the standard of treatment for PHC (40). A low-volume FLR is therefore often anticipated in these patients and a preoperative angio-CT for volumetric evaluation has to be part of the preoperative work-up for PHC.

An FLR volume of $>25-30 \%$ is considered a safe cutoff for patients with healthy liver parenchyma (41). However, in patients with compromised liver, as those with longstanding biliary obstruction or cholangitis, a higher risk of PHLF exists if the FLR is less than $40 \%$ (31, 42,43 ). Aprecise cut off in terms of FLR experienced in patients with cholangitis has not yet been established. Indeed, Olthof et al. showed that liver volumetry alone has low negative predictive value towards PHLF (44). Indeed, liver volume has been shown to not fully represent its function (45). Other factors have been associated to PHLF, such as jaundice at presentation and pre-operative bilirubin level > $50 \mathrm{umol} / \mathrm{L}(2.9 \mathrm{mg} /$ dl) (44) and cholangitis (46). Therefore, in addition to FLR volume, some scores have been proposed to identify patients undergoing surgery for $\mathrm{PHC}$ at risk of PHLF (44).

Liver functional tests as the clearance rate of the indocyanine green (ICG) and hepatobiliary scintigraphy with 99mTc-mebrofenin (HBS) are widely used in several centers to predict FLR function and the risk of PHLF.

ICG is the reference liver function test in the Eastern world. The safety of major liver resection planned on the base of preoperative ICG test has been shown in many series (47), even in case of PHC (48). An ICG clearance of the FLR less than 0.05 is associated with higher mortality after major liver resection for PHC (48).

HBS is gaining popularity as liver function teste specially in the Western World $(49,50)$. HBS well correlates with ICG, providing additional information regarding the function of specific areas of liver parenchyma (51). An uptake $<2.69 \% / \mathrm{min} / \mathrm{m}^{2}$ of the FLR has been associated with the risk of PHLF and mortality after extended hepatectomy (52). Recently the Amsterdam Medical Centre has included HBS as part of the preoperative work-up for PHC (40). The authors believe that HBS could provide additional information on the liver quality, but results on the HSB impact on PHLF in patients with PHC are still awaited.
Both tests present, however, an important limitation. Indeed, bilirubin, 99mT-mebrofenin, and indocyanine green share the same hepatocyte transporters (53). Hence, in patients with cholestasis, HBS and ICG could underestimate liver function, unless low bilirubin levels are obtained after adequate biliary drainage (54).

\section{PORTAL VEIN EMBOLIZATION AND ALPPS}

Since introduced by Makuuchi in 1982 (55), PVE is the standard technique to increase the FLR volume with minimal risks (56-58). Although PVE could promote tumor growth and influence oncological outcomes in case of metastases (59), it has been shown that PVE does not affect survival of patients with PHC (60). PVE seems to reduce significantly the risk of PHLF in case of extended hepatectomy, as reported by the Nagoya group (61).

Currently, indications for PVE include a FLR $<40 \%$ of the total liver volume $(40,62)$ or low function of the $\mathrm{FLR}$, quantified as an HBS function $<2.7 \% / \mathrm{min} / \mathrm{m}^{2}(40)$ or an ICG clearance of the FLR $<0.0548$ ). Recently, a score based on FLR volume, bilirubin level and cholangitis has been developed to select patients for PVE (44). Biliary drainage of the FLR should be obtained prior to PVE to improve its regeneration (58). In case of extended right hepatectomy, embolization of segment IV improves hypertrophy of the FLR (20). Following PVE, FLR hypertrophy less than $5 \%$ indicates a high risk for PHLF and liver resection should be contraindicated (58). The main drawback remains that PVE irreversibly determines the side of the resection, thus limiting the possibility of intraoperative changes in the surgical strategy (40).

Associating Liver Partition and Portal vein ligation for Staged hepatectomy (ALPPS) (63) has gained popularity for its ability to induce faster hypertrophy of the FLR. In addition, ALPPS could have an additional value in patients with PHC, allowing to decide the segments to resect and those that will remain on the base of an intraoperative assessment. However, the initial experience reported higher morbidity and mortality following ALPPS compared to major hepatectomies after PVE (63). In 2017, an analysis of from the international ALPPS registry specifically focusing on patients with PHC was published (64). ALPPS for PHC presented a higher 90 -day mortality (48\%) compared to major liver resection without ALPPS (13\%). Moreover, even after matching for FLR volume, ALPPS presented worse mortality and survival rates (6 vs 29 months) (64). On the base of this evidence, ALPPS cannot be 
recommended in a patient with PHC. Therefore, PVE has still to be considered the method of choice to increase the FLR volume in patients with PHC.

\section{CONCLUSIONS}

Preoperative management is pivotal for patients undergoing surgery for PHC with curative intent, although not high level of evidence is available. The operating surgeon should coordinate pre-operative interventions, which need to be patients-tailored and are in function of the surgical planning.

\section{Financial support}

The authors did not receive any financial support for this study.

\section{Disclosure}

None of the authors has potential conflicts to disclose.

\section{REFERENCES}

1. DeOliveira ML, Cunningham SC, Cameron JL, Kamangar F, Winter JM, et al. Cholangiocarcinoma: Thirty-one-year experience with 564 patients at a single institution. Ann Surg 2007; 245:755-62.

2. Blechacz B, Gores GJ. Cholangiocarcinoma: Advances in pathogenesis, diagnosis, and treatment. Hepatology 2008:48:308-21.

3. Liu F, Li Y, Wei Y, Li B. Preoperative biliary drainage before resection for hilar cholangiocarcinoma: Whether or not? A systematic review. Dig Dis Sci 2011;56:663-72.

4. Imamura H, Shimada R, Kubota M, Matsuyama $Y$, Nakayama A, Miyagawa S, et al. Preoperative portal vein embolization: an audit of 84 patients. Hepatology 1999;29:1099-105.

5. van der Gaag N a, Kloek JJ, de Castro SMM, Busch ORC, van Gulik TM, Gouma DJ. Preoperative biliary drainage in patients with obstructive jaundice: history and current status. J Gastrointest Surg 2009;13:814-20.

6. Abe T, Arai T, Ogawa A, Hiromatsu T, Masuda A, Matsuguchi T, et al. Kupffer cell-derived interleukin 10 is responsible for impaired bacterial clearance in bile duct-ligated mice. Hepatology 2004:40:414-23.

7. Sugawara G, Ebata T, Yokoyama Y, Igami T, Takahashi Y, Takara D, et al. The effect of preoperative biliary drainage on infectious complications after hepatobiliary resection with cholangiojejunostomy. Surg (United States) 2013:153:200-10

8. Nagino M, Takada T, Miyazaki M, Miyakawa S, Tsukada K, Kondo S, et al. Preoperative biliary drainage for biliary tract and ampullary carcinomas. J Hepatobiliary Pancreat Surg 2008;15:25-30.

9. Su CH, Tsay SH, Wu CC, Shyr YM, King KL, Lee CH, et al. Factors influencing postoperative morbidity, mortality, and survival after resection for hilar cholangiocarcinoma. Ann Surg 1996;223:384-94.

10. Nagino M, Ebata T, Yokoyama Y, Igami T, Sugawara G, Takahashi Y, et al. Evolution of Surgical Treatment for Perihilar Cholangiocarcinoma. Ann Surg 2013;258:129-40.

11. Ferrero A, Lo Tesoriere R, Viganò L, Caggiano L, Sgotto E, Capussotti L. Preoperative biliary drainage increases infectious complications after hepatectomy for proximal bile duct tumor obstruction. World J Surg 2009;33:318-25.

12. Takahashi $Y$, Nagino $M$, Nishio $H$, Ebata $T$, Igami $T$, Nimura $Y$, Percutaneous transhepatic biliary drainage catheter tract recurrence in cholangiocarcinoma. Br J Surg 2010;97:1860-6.

13. Cherqui D, Benoist S, Malassagne B, Humeres R, Rodriguez V, Fagniez PL. Major liver resection for carcinoma in jaundiced patients without preoperative biliary drainage. Arch Surg 2000;135:302-8.

14. Figueras J, Llado L, Valls C, Serrano T, Ramos E, Fabregat J, et al. Changing strategies in diagnosis and management of hilar cholangiocarcinoma. Liver Transpl 2000;6:786-94.

15. lacono C, Ruzzenente A, Campagnaro T, Bortolasi L, Valdegamberi A, Guglielmi A. Role of preoperative biliary drainage in jaundiced patients who are candidates for pancreatoduodenectomy or hepatic resection: Highlights and drawbacks. Ann Surg 2013:257:191-204.

16. Sewnath ME, Karsten TM, Prins MH, Rauws EJA, Obertop H, Gouma DJ. A meta-analysis on the efficacy of preoperative biliary drainage for tumors causing obstructive jaundice. Ann Surg 2002;236:17-27.

17. Farges 0 , Regimbeau JM, Fuks D, Le Treut YP, Cherqui D, Bachellier $P$, et al. Multicentre European study of preoperative biliary drainage for hilar cholangiocarcinoma. Br J Surg 2013;100:274-83.

18. Khan SA, Davidson BR, Goldin R, Pereira SP, Rosenberg WMC, Taylor-Robinson SD, et al. Guidelines for the diagnosis and treatment of cholangiocarcinoma: consensus document. Gut 2002; 51:vi1-vi9. doi:10.1136/gut.51.suppl_6.vi1.

19. Rerknimitr R, Angsuwatcharakon P, Ratanachu-ek T, Khor CJL, Ponnudurai R, Moon JH, et al. Asia-Pacific consensus recommendations for endoscopic and interventional management of hilar cholangiocarcinoma. J Gastroenterol Hepatol 2013;28:593-607.

20. Mansour JC, Aloia TA, Crane CH, Heimbach JK, Nagino M, Vauthey J-N. Hilar Cholangiocarcinoma: expert consensus statement. HPB (Oxford) 2015;17:691-9.

21. Kloek JJ, van der Gaag NA, Aziz Y, Rauws EAJ, van Delden OM, Lameris JS, et al. Endoscopic and percutaneous preoperative biliary drainage in patients with suspected hilar cholangiocarcinoma. J Gastrointest Surg 2009;14:119-25.

22. Jo JH, Chung MJ, Han DH, Park JY, Bang S, Park SW, et al. Best options for preoperative biliary drainage in patients with Klatskin tumors. Surg Endosc Other Interv Tech 2017;31:422-9.

23. Kim KM, Park JW, Lee JK, Lee KH, Lee KT, Shim SG. A comparison of preoperative biliary drainage methods for perihilar cholangiocarcinoma: Endoscopic versus percutaneous transhepatic biliary drainage. Gut Liver 2015;9:791-9.

24. Lee SH, Park JK, Yoon WJ, Lee JK, Ryu JK, Yoon YB, et al. Optimal biliary drainage for inoperable Klatskin's tumor based on Bismuth type. World J Gastroenterol 2007;13:3948-55.

25. Walter T, Ho CS, Horgan AM, Warkentin A, Gallinger S, Greig PD, et al. Endoscopic or percutaneous biliary drainage for Klatskin tumors? J Vasc Interv Radiol 2013:24:113-21.

26. Tang Z, Yang Y, Meng W, Li X. Best option for preoperative biliary drainage in Klatskin tumor: A systematic review and meta-analysis. Medicine (Baltimore) 2017:96:e8372.

27. Hirano S, Tanaka E, Tsuchikawa T, Matsumoto J, Kawakami H, Nakamura T, et al. Oncological benefit of preoperative endoscopic biliary drainage in patients with hilar cholangiocarcinoma. J Hepatobiliary Pancreat Sci 2014;21:533-40.

28. Kawakubo K, Kawakami H, Kuwatani M, Haba S, Kudo T, Taya YA, et al. Lower incidence of complications in endoscopic nasobiliary drainage for hilar cholangiocarcinoma. World J Gastrointest Endosc 2016;8:385

29. Kawakami H, Kuwatani M, Onodera M, Haba S, Eto K, Ehira N, et al. Endoscopic nasobiliary drainage is the most suitable preoperative biliary drainage method in the management of patients with hilar cholangiocarcinoma. J Gastroenterol 2011;46:242-8.

30. Ishizawa T, Hasegawa K, Sano K, Imamura H, Kokudo N, Makuuchi M. Selective versus total biliary drainage for obstructive jaundice caused by a hepatobiliary malignancy. Am J Surg 2007;193:149-54.

31. Belghiti J, Ogata S. Preoperative optimization of the liver for resection in patients with hilar cholangiocarcinoma. HPB 2005;7:252-3.

32. Kawasaki S, Imamura H, Kobayashi A, Noike T, Miwa S, Miyagawa SI. Results of Surgical Resection for Patients with Hilar Bile Duct Cancer: Application of Extended Hepatectomy after Biliary Drainage and Hemihepatic Portal Vein Embolization. Ann Surg 2003;238: 84-92.

33. Saiki S, Chijiiwa K, Komura M, Yamaguchi K, Kuroki S, Tanaka M. 
Preoperative internal biliary drainage is superior to external biliary drainage in liver regeneration and function after hepatectomy in obstructive jaundiced rats. Ann Surg 1999;230:655-62.

34. Suzuki H, lyomasa S, Nimura Y, Yoshida S. Internal biliary drainage, unlike external drainage, does not suppress the regeneration of cholestatic rat liver after partial hepatectomy. Hepatology 1994; 20:1318-22.

35. Kamiya S, Nagino M, Kanazawa H, Komatsu S, Mayumi T, Takagi K, et al. The Value of Bile Replacement during External Biliary Drainage: An Analysis of Intestinal Permeability, Integrity, and Microflora. Ann Surg 2004;239:510-7.

36. Nimura Y, Kamiya J, Kondo S, Nagino M, Uesaka K, Oda K, et al. Aggressive preoperative management and extended surgery for hilar cholangiocarcinoma: Nagoya experience. J Hepatobiliary Pancreat Surg 2000;7:155-62.

37. Sugawara G, Nagino M, Nishio H, Ebata T, Takagi K, Asahara T, et al. Perioperative synbiotic treatment to prevent postoperative infectious complications in biliary cancer surgery: A randomized controlled trial. Ann Surg 2006;244:706-14.

38. Nimura Y, Hayakawa N, Kamiya J, Kondo S, Shionoya S. Hepatic segmentectomy with caudate lobe resection for bile duct carcinoma of the hepatic hilus. World J Surg 1990;14:535-43.

39. Dinant S, Gerhards MF, Busch ORC, Obertop H, Gouma DJ, Van Gulik TM. The importance of complete excision of the caudate lobe in resection of hilar cholangiocarcinoma. HPB 2005;7:263-7.

40. Rassam F, Roos E, van Lienden KP, van Hooft JE, Klümpen HJ, van Tienhoven G, et al. Modern work-up and extended resection in perihilar cholangiocarcinoma: the AMC experience. Langenbeck's Arch Surg 2018:1-19.

41. Ferrero $A$, Viganò L, Polastri R, Muratore A, Eminefendic $H$, Regge D, et al. Postoperative liver dysfunction and future remnant liver: Where is the limit? Results of a prospective study. World J Surg 2007;31:1643-51.

42. Farges 0 , Belghiti J, Kianmanesh R, Regimbeau JM, Santoro R, Vilgrain V, et al. Portal Vein Embolization before Right Hepatectomy: Prospective Clinical Trial. Ann Surg 2003;237:208-17.

43. Wiggers JK, Groot Koerkamp B, Cieslak KP, Doussot A, van Klaveren D, Allen PJ, et al. Postoperative Mortality after Liver Resection for Perihilar Cholangiocarcinoma: Development of a Risk Score and Importance of Biliary Drainage of the Future Liver Remnant. J. Am. Coll. Surg., vol. 223, 2016, p. 321-331.e1.

44. Olthof PB, Wiggers JK, Groot Koerkamp B, Coelen RJ, Allen PJ, Besselink MG, et al. Postoperative Liver Failure Risk Score: Identifying Patients with Resectable Perihilar Cholangiocarcinoma Who Can Benefit from Portal Vein Embolization. J Am Coll Surg 2017;225:387-94.

45. Olthof PB, Tomassini F, Huespe PE, Truant S, Pruvot FR, Troisi RI, et al. Hepatobiliary scintigraphy to evaluate liver function in associating liver partition and portal vein ligation for staged hepatectomy: Liver volume overestimates liver function. Surgery 2017.

46. Ribero D, Zimmitti G, Aloia TA, Shindoh J, Forchino F, Amisano M, et al. Preoperative cholangitis and future liver remnant volume determine the risk of liver failure in patients undergoing resection for hilar cholangiocarcinoma. J Am Coll Surg 2016;223:87-97.

47. Imamura H, Seyama Y, Kokudo N, Maema A, Sugawara Y, Sano K, et al. One Thousand Fifty-Six Hepatectomies without Mortality in 8 Years. Arch Surg 2003;138:1198-206.

48. Yokoyama Y, Ebata T, Igami T, Sugawara G, Mizuno T, Yamaguchi J, et al. The Predictive Value of Indocyanine Green Clearance in Future Liver Remnant for Posthepatectomy Liver Failure Following
Hepatectomy with Extrahepatic Bile Duct Resection. World J Surg 2016:40:1440-7.

49. Bennink RJ, Dinant S, Erdogan D, Heijnen BH, Straatsburg IH, van Vliet AK, et al. Preoperative assessment of postoperative remnant liver function using hepatobiliary scintigraphy. J Nucl Med. 2004; 45:965-71.

50. Erdogan D, Heijnen BH, Bennink RJ, Kok M, Dinant S, Straatsburg $\mathrm{IH}$, et al. Preoperative assessment of liver function: a comparison of 99mTc-Mebrofenin scintigraphy with indocyanine green clearance test. Liver Int 2004;24:117-23.

51. Erdogan D, Heijnen BHM, Bennink RJ, Kok M, Dinant S, Straatsburg $\mathrm{IH}$, et al. Preoperative assessment of liver function: a comparison of 99mTc-Mebrofenin scintigraphy with indocyanine green clearance test. Liver Int 2004;24:117-23.

52. de Graaf W, van Lienden KP, Dinant S, Roelofs JJ, Busch OR, Gouma DJ, et al. Assessment of future remnant liver function using hepatobiliary scintigraphy in patients undergoing major liver resection. J Gastrointest Surg 2010;14:369-78.

53. De Graaf W, Häusler S, Heger M, Van Ginhoven TM, Van Cappellen G, Bennink RJ, et al. Transporters involved in the hepatic uptake of 99mTc-mebrofenin and indocyanine green. J Hepatol 2011; 54:738-45.

54. Keppler D. The roles of MRP2, MRP3, OATP1B1, and OATP1B3 in conjugated hyperbilirubinemia. Drug Metab Dispos 2014;42:561-5.

55. Makuuchi M, Thai BL, Takayasu K, Takayama T, Kosuge T, Gunvén P, et al. Preoperative portal embolization to increase safety of major hepatectomy for hilar bile duct carcinoma: a preliminary report. Surgery 1990;107:521-7.

56. Nagino M, Kamiya J, Nishio H, Ebata T, Arai T, Nimura $\mathrm{Y}$. Two hundred forty consecutive portal vein embolizations before extended hepatectomy for biliary cancer: Surgical outcome and long-term follow-up. Ann Surg 2006;243:364-72.

57. Abulkhir A, Limongelli P, Healey AJ, Damrah O, Tait P, Jackson J, et al. Preoperative portal vein embolization for major liver resection: a meta-analysis. Ann Surg 2008;247:49-57.

58. Palavecino M, Abdalla EK, Madoff DC, Vauthey J-N. Portal vein embolization in hilar cholangiocarcinoma. Surg Oncol Clin N Am 2009;18:257-67, viii.

59. Giglio MC, Giakoustidis A, Draz A, Jawad ZAR, Pai M, Habib NA, et al. Oncological Outcomes of Major Liver Resection Following Portal Vein Embolization: A Systematic Review and Meta-analysis. Ann Surg Oncol 2016;23.

60. Glantzounis GK, Tokidis E, Basourakos SP, Ntzani EE, Lianos GD, Pentheroudakis $G$. The role of portal vein embolization in the surgical management of primary hepatobiliary cancers. A systematic review. Eur J Surg Oncol 2017;43:32-41.

61. Nishio $H$, Nagino M, Nimura Y. Surgical management of hilar cholangiocarcinoma: The Nagoya experience. HPB 2005;7:259-62.

62. Higuchi R, Yamamoto M. Indications for portal vein embolization in perihilar cholangiocarcinoma. J Hepatobiliary Pancreat Sci 2014; 21:542-9.

63. Schadde E, Ardiles V, Robles-Campos R, Malago M, Machado M, Hernandez-Alejandro R, et al. Early survival and safety of ALPPS first report of the international ALPPS registry. Ann Surg. 2014; 260:82936; discussion 836-8.

64. Olthof PB, Coelen RJS, Wiggers JK, Groot Koerkamp B, Malago M, Hernandez-Alejandro R, et al. High mortality after ALPPS for perihilar cholangiocarcinoma: case-control analysis including the first series from the international ALPPS registry. HPB 2017; 19:381-7. 